\title{
Ethnomedicinal Selected Herbal Plants in the Management of Diabetes: An Updated Review
}

\section{Jhakeshwar Prasad ${ }^{1 *}$, Divya Sahuํㅜ, Trilochan Satapathy ${ }^{2}$, Parag Jain ${ }^{3}$ and Deepak Kashyap ${ }^{4}$}

${ }^{1}$ RITEE, College of Pharmacy, Chhatauna Mandir Hasaud, Chhattisgarh, India

${ }^{2}$ University College of Pharmacy, Pt. Deendayal Upadhyay Memorial Health Sciences

and Ayush University, Chhattisgarh, India

${ }^{3}$ Chhattrapati Shivaji Institute of Pharmacy, Chhattisgarh, India

${ }^{4}$ Sanjivani Institute of Pharmacy Ganiyari, Chhattisgarh, India

*Corresponding Author: Jhakeshwar Prasad, RITEE, College of Pharmacy, Chhatauna Mandir Hasaud, Chhattisgarh, India.
Received: August 14, 2021

Published: September 23, 2021

(C) All rights are reserved by Jhakeshwar

Prasad., et al.

\section{Abstract}

Diabetes mellitus has become a global epidemic over the past few decades and is one among the major causes of death worldwide. Although various modern medicines are in the market, herbal medicines have usually maintained worldwide popularity in achieving the primary health care needs of the diabetic population because of the multiple adverse effects related to them. Herbal medicines have a prolonged history of being used as medications and sources of medication for diabetes mellitus. Some of them are enclosed within the modern therapeutic arsenal of medicine, and others are used as complementary therapy or as dietary supplements by patients with diabetes. This present review focused on the herbs, the hypoglycemic actions of which have been supported by three or more clinical studies. According to the clinical studies, Allium sativum, Curcuma Longa, Gymnema sylvestre, Momordica charantia, Stevia rebaudiana have shown hypoglycemic and, in some cases, hypolipidemic activities in diabetic patients. Thus, it seems that physicians can rely on these herbs and advise for the patients to improve management of diabetes.

Keywords: Diabetes; Herbal Medicinal Plants; Macroscopic Character; Chemical Constituents; Uses

\section{Introduction}

Type 2 Diabetes Mellitus is increasing alarmingly day by day. Starting from aged persons to young ones even children are also suffering from this epidemic disorder. Type 2 diabetes is a metabolic disorder which is characterized by hyperglycemia resulting from defective insulin secretion, resistance to insulin action or both [1]. Hyperglycemia occurs when blood sugar levels become too high (above $200 \mathrm{mg} / \mathrm{dl}$ ). Some other factors like consumption of more carbohydrates than usual, less or no physical activity, being ill or having an infection, increase in stress, not getting proper dose of medicines etc. are also responsible for causing this. In early stage different symptoms like frequent urination, increased thirst, blurred vision, fatigue, headache, etc. are noticed. Later if untreated, other complications crop up like fruity-smelling breath, nausea, vomiting, shortness of breath, dry mouth, weakness, confusion, coma, abnormal activity. Long term damage of target organs like heart, kidney and nerves leading to cardiovascular complications, diabetic neuropathy (damage of nerve cells), kidney damage or Congestive Kidney Failure (CHF), diabetic retinopathy (damage of retinal blood vessels), cataract, diabetic foot infection, bone and joint problems etc. also develop [2]. Generally, simple carbohydrate, Glucose formed from complex carbohydrates is directly absorbed into the bloodstream but cannot enter the body cells without the help of insulin. Insulin plays a vital role in controlling high blood sugar level. Any defect in insulin production and action leads to serious metabolic disorders. Insulin in normal dose 
is not able to activate the cells to take up the glucose. So, they want more amount of insulin for cell's sensitization and thereby help to transport a special transporter, GLUT 4 and Hexokinase to the cell surface. GLUT 4 is found in adipose tissues and skeletal/cardiac muscles and is known to be responsible for the regulation of cellular glucose uptake upon stimulation caused by external factors, such as insulin and exercise. Various factors like Genetic factors, environmental factors, metabolic hormones (leptin, adiponectin, glucagon), excess nutrients, systemic free fatty acids, ER stress/ oxidative stress, adipose hypoxia etc. play the role for generation of insulin resistance. Various chemical medications like insulin therapy, acarbose, miglitol (Alpha Glucosidase Inhibitors), metformin (Biguanides), dopamine agonist (Bromocriptine), DPP-4 inhibitors, glucagon like peptides, SGLT-2 inhibitors, etc. are used to cure this disease but due to their critical and deleterious complications and reported side-effects (skin rash, sickness with alcohol, kidney damage, gas, bloating, diarrhea, stomach upset, etc.) people are being scared to use it [3].

\section{Allium sativum}

\section{Biological source}

This consists of bulbs of the plant known as Allium sativum Linn. Family known as Allium sativum Linn. family Liliaceae. It contains not less than 0.2 per cent of alliin on dried basis.

\section{Geographical source and collection}

Lahsun is cultivated in Central Asia, Southern Europe. USA, and India. In India, it is found in most all the states and cultivated as a spice or a condiment crop.

\section{Cultivation and collection}

Garlic is cultivated in well-drained moderately clay loamy soil. It needs cool moist climatic conditions during the growth and dry period during maturity. Garlic is a hardy perennial with narrow flat leaves and bears white small flowers and bul-bils. The cultivation of drug is done by planting bulbs generally in the month of September to late in October. It takes about four months for harvesting. It is also taken as an alternate crop with many other vegetables. For cultivation, about $300 \mathrm{~kg}$ of bulbs per hectare are required, and yield per hectare is about $8,000 \mathrm{~kg}$.

\section{Macroscopic characters}

- Colour - Bulbs are white to pink in colour.
- $\quad$ Odour - Characteristic and aromatic.

- $\quad$ Taste - Aromatic and pungent.

- $\quad$ Size -1.5 to $2.5 \mathrm{~cm}$

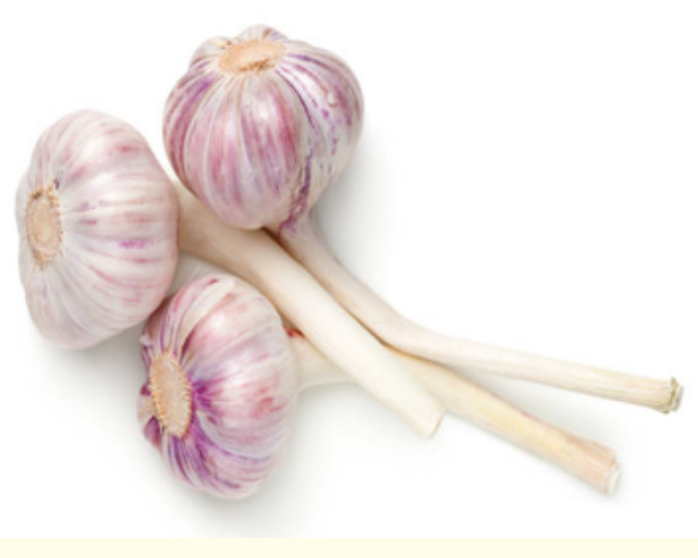

Figure 1: Allium sativum.

\section{Chemical constituents}

Garlic bulbs contain 29 percent of carbohydrates, about 56 percent of proteins (albumin), 0.1 percent of fat, mucilage, and 0.06 to 0.1 per cent of volatile oil. It also contains phosphorus, iron and copper. Volatile oil of the drug is the chief active constituent, and contains ally! propyl disulphide, diallyl disulphide, alliin and allicin. Alliin by action of enzyme allinlyase is converted into allicin. Garlic oil is yellow in colour and has specific gravity of 1.046. It is optically inactive.

\section{Uses}

Garlic is used as carminative, aphrodisiac, expectorant, stimulant, and disinfectant in the treatment of pulmonary conditions. It is largely used as condiment. Oil of garlic is used as anthelmintic and rubefacient. Allicin is antibacterial. Garlic oil is useful in high blood pressure and atherosclerosis. Fresh garlic is prophylactic against amoebic dysentery.

Storage

It undergoes degradation and hence, should be carefully stored at zero degree centigrade and 65 per cent of relative humidity [4]. 


\section{Curcuma longa}

Biological source

Turmeric consists of dried, as well as, fresh rhizomes of the plant known as Curcuma longa Linn. (C. domestica), belonging to family Zingiberaceae. It contains not less than 1.5 percent of curcumin.

\section{Geographical source}

India accounts for as much as, 90 percent of the total output of the world. Tamil Nadu and Andhra Pradesh together contribute about 70 per cent of the Indian production. Kerala also produces large quantity of turmeric. It is very superior in quality and is exported on large scale. At present, about 1, 07,800 hectares of land is under cultivation of turmeric with 2, 94,900 tones of production. In the year 1996-97, India exported 155 tonnes of turmeric-oleoresin of the value of 868 lacs. Curcuma is a genus of about 70 species of rhizomatous herbs distributed in South East Asia and especially India, China, Thailand, Italy, Malaysia, Archipelago and N. Australia. Commercially, C. amada. C. angustifolia, C. aromatica, C. caesia, C. zedoaria and c. longa are important. Out of these. C. longa (turmeric) is more important due to its uses like spice, condiment, antiseptic in bruises, anti-inflammatory and in sprains. It has long been known traditionally as a nature, for dyeing wool and silk. Most of the species are perennial herbs which grow 2 - $3 \mathrm{ft}$ short stem and tufted leaves. Rhizome is the product of commerce.

\section{Cultivation and collection}

C. longa (turmeric) is the main species of commerce and is cultivated for its rhizomes China and also in Sri Lanka, Indonesia, Jamaica and Peru. India is the major grower with almost hectares under this crop producing 1, 44,000 tonnes per annum. In 1994 - 95, it exporter tones of turmeric worth Indian 44.59 crores. The plants are grown for 7 - 9 months after which rhizomes (both mother and finger) are harvested, cooked, dried and then processed for powder oleo resin and Curcumin. The extraction of powder is carried out by using solvents, water or be Diseases and insects are known for which proper methods of control are available. Gen improvements have been attempted and five high yielding varieties have been developed. $\mathrm{H}$ yielding Curcumin varieties have been evolved through tissue culture techniques; clonal propagation has been successfully developed in case of $C$. longa.

\section{Macroscopic characters}

Externally, the drug is yellowish-brown in colour with characteristic odour and slightly bitter taste. Round turmeric rhizomes are oblong, while long variety is cylindrical and short branched. Root scars and annulations are present. The fracture is horny and internal surface is orange. Rhizomes are 5 to $10 \times 2$ to $4 \mathrm{~cm}$. in size.

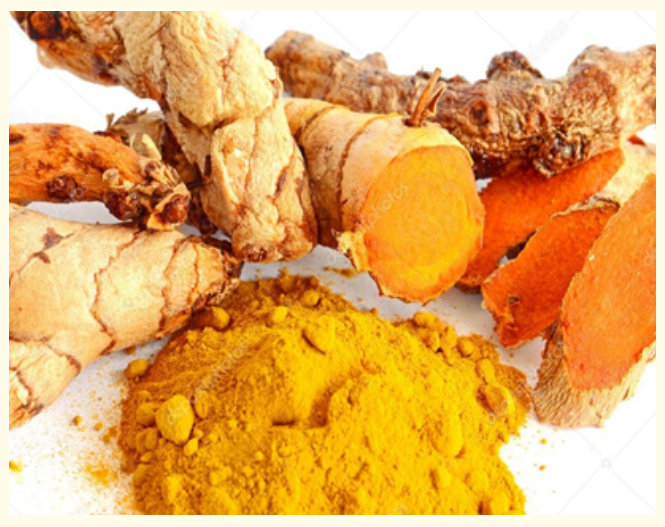

Figure 2: Curcuma Longa.

\section{Microscopic characters}

The transverse section of turmeric rhizome shows the outermost 4 to 6 layers of brick shaped parenchymatous cork, followed by cork cambium. The cortex consists of thin walled rounded parenchymatous cells containing scattered vascular bundles. Oleoresin cells with brownish contents are also observed throughout the ground tissue. Oil cells have suberised cell-walls. Vascular bundles are present in cortex and are collateral. Vascular bundles in pith region are scattered forming discontinuous ring under endodermis. Endodermis is well marked and starch grains (5 to 15 in diameter) are abundant.

\section{Chemical constituents}

Turmeric contains about 5 percent of volatile oil, resin; abundant zingiberaceous starch grains and yellow colouring substances known as curcuminoids. The chief component of curcuminoids is known as curcumin (50 - 60 per cent). Chemically, Curcuma species contain volatile oil, starch and curcumin. Curcumin and other related curcuminoids such as Demethoxy curcumin and Demethoxy curcumin are reported to be responsible for the yellow colour in some species. Volat oil content ranges from $1-6.5$ per cent and is composed of mono and sesquiterpene such as alpha and beta pinene, a-phellandrene, camphor, camphene, DL-r-termerone zingiberene and a, $ß$ curcumene Species like $C$. angustifolia and $C$. caulina have high starch content and are used as a substitute for arrow root.

\section{Standards}

- $\quad$ Foreign organic matter - not more than 2.0 per cent

- $\quad$ Ash - not more than 8.0 per cent

- Water soluble extractive - not less than 9.0 per cent 
- $\quad$ Alcohol-soluble extractive - not less than 10.0 percent

- $\quad$ Moisture - not more than 10.0 per cent

Chemical tests

- $\quad$ Powdered drug with sulphuric acid gives crimson colour.

- The aqueous solution of turmeric with boric acid gives reddish-brown colour which on addition of alkali changes to greenish-blue.

- With acetic anhydride and concentrated sulphuric acid, it gives violet colour. When this test is observed under ultraviolet light, red fluorescence is seen.

Uses

Turmeric is used as a condiment or spice, and coloring agent, especially for ointments and creams. Chemically, it is used for the detection of boric acid. It is antiseptic and anti-inflammatory too. Curcumin is also powerful antioxidant. Turmeric/Curcumin are official in various pharmacopoeias. Apart from traditional uses, Curcumin has been proved as anti-inflammatory drug. Anti-arthritic agent has been isolated from $C$. aromatic. In China, $C$. wenyjuin ( $C$. aromatic) has been used in cervical cancer. Curcumin has been defined by International Standards Organisation (ISO 5562-1983) and British Standards (BS 6147: 1983). It is estimated both by colorimetry and HPLC. G.L.C. and T.L.C. methods are also reported for various constituents. 30th report of WHO/FAO expert committee on food additives has included Curcumin. Curcuminoids isolated from ethyl acetate extract of turmeric have shown modest HIV-1 and HIV-2 protease inhibitory activity [5].

\section{Gudmar}

\section{Biological source}

This consists of the leaves of a perennial woody climber plant known as Cymnema sylvestre belonging to family Asclepiadaceae. It contains not less than 1.0 per cent of Gymnemic acids calculated on semagenin on dried basis. Gymnemagenin.

\section{Geographical distribution}

It is a woody climber found in India, common Deccan-peninsula Western parts of India peninsula and also in Northern and south of India. It is occasionally cultivated for medicinal purposes.

\section{Macroscopic characters}

- $\quad$ Colour - Green

- Odour - Pleasant and aromatic odour
- $\quad$ Taste - Tasteless

- $\quad$ Size- 3-5 1 - $2 \mathrm{~cm}$

- $\quad$ Shape - elliptic or ovate with acute or acuminate apex

The leaves when chewed have remarkable property of paralysing the taste glands for few hours against sweet and bitter taste.

Lower surface of leaf is more pubescent and base is rounded or cordate. Non-glandulartrichomes are present on both the surfaces of leaf. It bears small yellow coloured flowers in the form of cymes.

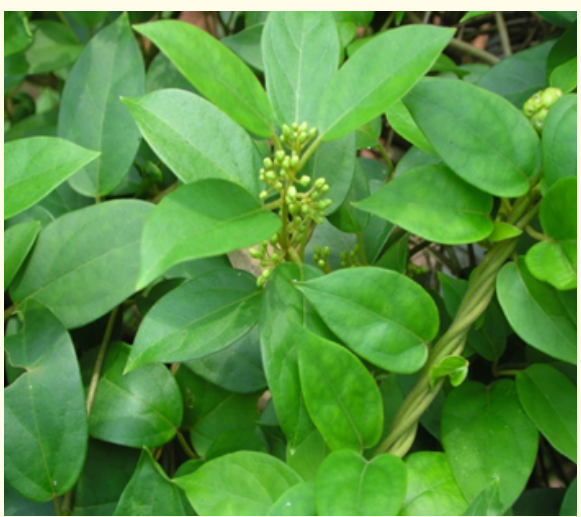

Figure 3: Gymnema sylvestre.

\section{Chemical constituents}

The leaves contain pentriacontane, hentriacontane, phytin, a and $ß$ chlorophylls, resin, tartaric ermic acid, butyric acid, mucilage inositol, d-quercitol, gymnemic acids (anti-sweet os), the mixture of triterpene saponines and anthraquinone derivatives. The plant is reported to contain alkaloids, betain, choline and trimethylamine in the leaves.

Nyrin, stigmesterol are also present in the leaves. mic acid is a mixture of at least nine closely related acidic glycosides fractionated by action with different solvents. Ethyl acetate fraction of such gymnemic acid mixture ng effect on taste glands. Gypenosides have also been isolated from leaves.

\section{Chemical tests}

- Dilute solution anaesthetises sweet taste buds.

- Gives copious foam after shaking with water and on addition of dil hydrochloric acid forms voluminous precipitate. 
Uses

It is used as antidiabetic, stomachic, stimulant, laxative and diuretic. The antidiabetic formulations of this drug are commercially available. Hypoglycemic effect is due to indirect stimulation of insulin secretion by pancreas. Dental plaque and caries are prevented by gymnemic acids. Recently the drug has received world attention due to its weight-lowering properties. Indian exports of Gymnema extracts during 1996-1997 was reported to be Rs. 65 lakhs. The leaves of $G$. hirsutum and G. montanum of Western ghats are the substitute for Gymnema G. tingens and G. acuminatum are other species of Gymnema and used also for other purposes [6].

\section{Momordica}

\section{Biological source}

Karela consists of fresh green fruits of the plant known as $\mathrm{Mo}$ mordica charantia Linn, Cucurbitaceae.

\section{Cultivation}

It is a genus of annual or perennial climbers found throughout India and regularly cultiva.com an vegetable up to an altitude of $1500 \mathrm{~m}$. It is cultivated during warm season i.e. during April to July by using 2 - 3 seeds in apa are prepared at a distance of half a meter and provided with manures. Only one plant is! and seedlings are watered once or twice a week. Plants begin to flower 30 - 35 days after: and the fruits are ready for harvesting 15 - 20 days after flowering.

\section{Macroscopic character}

- Colour: Dark green to whitish green

- $\quad$ Odour: Characteristic

- $\quad$ Taste: Intensely bitter

- Size: 0.5 - $25 \mathrm{~cm}$ long, 2 - $4 \mathrm{~cm}$ wide

- Shape: Pendulous, fusiform and beaked. It is ribbed with numerous tubercles; fruits contain numerous brownish seeds embedded in red pulp.

Stems are slender and pubescent. The leaves of karela are suborbicular, 5 - 7 lobed, pubescent or sub-glabrous; flowers are solitary.

\section{Chemical Constituents:}

The fruits and leaves contain charantin, a steroidal saponin which shows blood sugar lowering activity. Karela fruits even con-

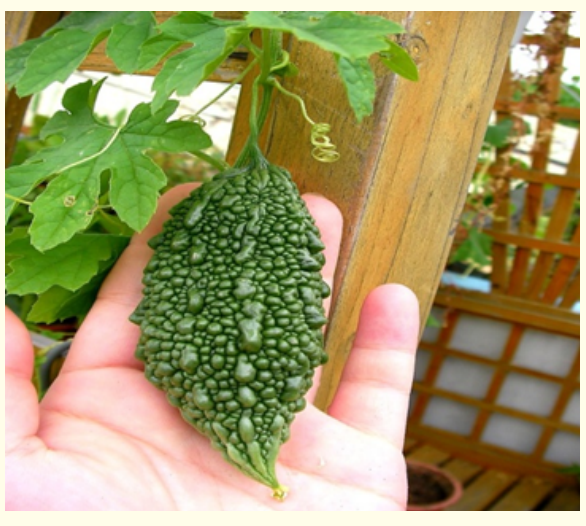

Figure 4: Momordica charantia.

tain a cathartic principle called momordicin. The drug also contains carbohydrates (10 per cent), mineral matter (1.5 per cent) and ascorbic acid (88 - $188 \mathrm{mg} / 100 \mathrm{gm})$. Additionally, alkaloids, glycoside, saponins, and mucilage are the other contents of Karela.

Uses

Karela is stomachic, reumatism, gout a Blood sugar level is stomachic, carminative, tonic and cooling and also used for the treatment of "gout and disorders of spleen and liver. Fruits, as well as, juice of fresh fruits reduce the "level and hence used for treatment of diabetes mellitus [7].

\section{Stevia}

Stevia natural sweetner is also symbolised as honey plant. Due to its high potency sweetening property, in future stevia is likely to be superior to chemical and synthetic sweetner, as well as sugar too. Its real wonder herb which is 300 times sweeter than sugar along with calorie free property.

\section{Biological source}

These are dried roots and leaves of plant Stevia rebaundiana Bertoni belonging to family Asteraceae (Compositae).

\section{Geographical source}

It is native of Paraguay (also known as sweet herb of Paraguay) and Brazil. Now cultivated in Canada, China, Japan, USA, Mexico, Indonesia, Korea and also to some extent in India.

\section{Cultivation and collection}

Subtropical climatic conditions are favourable for its growth. High temperature during day time and semi humid condition pro- 
mote its faster growth. Grows well upto an altitude of 200 to 250 meters from sea-level. Minimum $10^{\circ} \mathrm{C}$ during night and between $30^{\circ} \mathrm{C}$ to $35^{\circ} \mathrm{C}$ during day time. Well distributed rainfall ranging between 100 to $150 \mathrm{~cm}$ is favourable for its growth.

In India cultivation is done from April to June or August to September if there are heavy rains. Distance between two plants is maintained 25-30 cm and in between two rows 45-50 cm. Exposure to sunlight upto $40^{\circ} \mathrm{C}$ is essential. It doesn't tolerate saline soil with water logging. Hence, should be grown on red laterite calcareous soil with rich organic matter and well drained property with a pH between 4 - 5. It can be propagated either by seeds or vegetatively by using rooted plantlets. But due to poor seed germination (only 10 per cent vegetative propagation is prefered. It is a perennial plant. After 2 - 3 months from transplanting it starts bearing flowers.

The appropriate timing" harvesting this herb is period just before it starts flowering, when the active constituents are at their maximum in the leaves. The plants are cut at their base leaving 10 to $15 \mathrm{~cm}$ stem for regeneration of the crop. After first harvesting, the crop is again supplied with top dressing of nitrogen and irrigated. The procedure is repeated after every harvest. The crop is then ready after 45 days of first harvest". In this way harvesting can be carried out after every 45 days for three consecutive years. Whole plant is dried in shade for 3 - 4 days. Then the leaves are separated from the plant. Which used for preparation of powder. Depending upon the number of plucking the leaves ( 3 to 6 times in a year) 2000 to $4000 \mathrm{~kg}$ leaves, can be collected per hectare.

\section{Macroscopic characters}

- Leaves Colour: Green

- $\quad$ Odour: None

- $\quad$ Taste: Sweet, Liquorice-like

- $\quad$ Size: $5 \mathrm{~cm}$ in length, $3 \mathrm{~cm}$ in width

- Shape: Ovate

- $\quad$ Extra Features: Leaves, petiolate, acuminate, crenate faces are glabrons, planted crosswise, facing each other pubescent.

- $\quad$ Flowers: White, throats funnel form lobes 5.
Stavia is an erect, cauline, perennial, herbaceous plant about 50 - $100 \mathrm{~cm}$ in height. Dry weight of single plant about 70 gram.

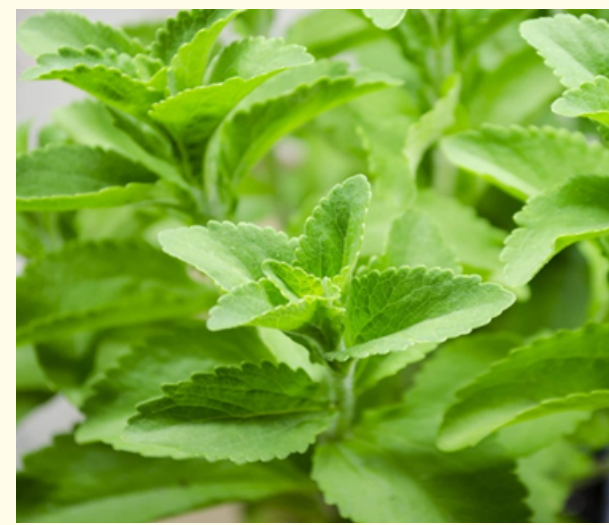

Figure 5: Stevia rebaudiana.

\section{Chemical constituents}

Total sweet glycoside concentration as Stevioside (5-10 per cent); Rebaudioside-A (2 - 4 per cent), Rebaudioside-C (1 - 2 per cent), Dulcoside - A (0.4 -0.7 per cent), Amongst these stevioside is the major component, besides these it also contains good amount of sterols, triternepes, flavonoids, tannins and also negligible amount of volatile oil.

Uses

Several therapeutic uses of stevia are reported amongst them antidiabetic is the major. It also shows antibacterial, anti-fertility, anti-inflammatory, antiseptic properties. It is also used as digestive tonic. It has shown good results in clearing up skin problems like, acne, seborrhea, dermatitis, eczema etc. [8].

\section{Conclusion}

This review focuses on recent literature evaluating naturally occurring antioxidants with respect to their impact on diabetes.

\section{Bibliography}

1. Kharroubi AT and Darwish HM. "Diabetes mellitus: The epidemic of the century". World Journal of Diabetes 6.6 (2015): 850. 
2. Laha S and Paul S. "Gymnema sylvestre (Gurmar): A potent herb with anti-diabetic and antioxidant potential”. Pharmacognosy Journal 11.2 (2019).

3. Paniagua JA. "Nutrition, insulin resistance and dysfunctional adipose tissue determine the different components of metabolic syndrome". World Journal of Diabetes 7.19 (2016): 483.

4. Kokate CK., et al. "A text book of Pharmacognosy". Nirali Prakashan 2 (2021): 1.51-1.52

5. Kokate CK., et al. "A text book of Pharmacognosy". Nirali Prakashan 2 (2021): 1.113-1.115

6. Kokate CK., et al. "A text book of Pharmacognosy". Nirali Prakashan .1 (2021): 8.98-8.99

7. Kokate CK., et al. "A text book of Pharmacognosy". Nirali Prakashan 1 (2021): 8.57-8.58

8. Kokate CK., et al. "A text book of Pharmacognosy". Nirali Prakashan 1 (2021): 8.101-8.103

Volume 4 Issue 10 October 2021

(C) All rights are reserved by Jhakeshwar Prasad., et la. 